\title{
Interorganizational network classification - A framework for studying industrial networks
}

\author{
Charles Møller, Jens Ove Riis, Mark Hansen \\ Department of Production, Aalborg University \\ Fibigerstrcede 16, DK-9220 Aalborg Ø, Denmark \\ E-mail:i9cm@iprod.auc.dk,
}

\begin{abstract}
The previous IFIP WG 5.7 working conference (Schönsleben, 1997) focused on the Extended Enterprise concept which this paper will elaborate on. Several important issues were addressed, and the conference and its proceedings included quite a broad spectrum of different situations. The discussions also revealed a need for clarifications of the concepts, and thus, the time is ripe for a classification effort.

Many researchers have carried out the study of interorganizational networks from different perspectives like e.g. organization theory, strategy, marketing, supply chain management etc. This paper proposes a theoretical framework for studying interorganizational networks from a manufacturing perspective.

By suggesting this framework we hope to stimulate the ongoing discussions of different manufacturing concepts and their relationships, and particulary the interorganizational issues.
\end{abstract}

Key Words

Extended Enterprise, Lean Production, Mass Customization, Agile

Manufacturing 


\section{BACKGROUND}

For several years the research communities studied what has been characterized as "post mass production" paradigms. Presently, Lean Production, Mass Customization and Agile Manufacturing attract most interest, but also concepts like Time-base Management, Holonic Manufacturing or the Fractal Factory have provided important new insights into manufacturing. Literature floods with imaginative acronyms and "new" concepts or "paradigms". Naturally, variety in tools and concepts enriches man's perception of reality. The disadvantage is due to the fact that we tend to forget that the concepts are only images of more or less the same manufacturing environment and situations, and that only when we combine all perspectives, real insight is gained.

Another important fact is that most concepts agree with the competitive situations and consent the strategic challenges, and the solution elements we can point to, are identical no matter which concept is applied. Examples are just-intime manufacturing, total quality management, kaizen, integration, electronic data interchange, process orientation, supply chain management, learning, empowerment, concurrency, etc. To a large extent the "best practice" manufacturing is determined by technological developments, particularly in IT, independent of the "paradigm of the month". The different new concepts provides us with a particular "mind-set" for differentiating the situations we are studying and thus expresses the partial knowledge about organizing people and technologies for manufacturing for general classes of situations.

The last fact is that the concepts we use often are vague and furthermore the definitions are inconsistent and overlapping. This suggests that a different approach is needed.

This paper will take a pragmatical point of departure in the situational theory (Riis, 92) and present examples of interorganizational network classes and discuss the problems of studying them, and finally suggest a theoretical framework for studying industrial networks from a manufacturing perspective. In the last part of the paper we will discuss the implication of this approach. First the concepts that are applied to the networks are discussed and defined and related.

\section{CONCEPTS}

In this chapter the concepts are defined and related to each other. The concepts in question are: The Extended Enterprise, Virtual Organizations, Lean Production, Mass Customization and Agile Manufacturing. These concepts have been chosen because most new literature seems to converge here.

\subsection{The Extended Enterprise}

Extended Enterprise is a concept, which have been used to characterize the global supply chain of a single product in an environment of dynamic networks of companies engaged in many different complex relationships. The interorganisational network may be defined as a system consisting of all the 
relevant functions of a company, its suppliers and its customers, who together are termed the extended enterprise.

The distinction between a "Company" and an "Extended Enterprise" is suggested in the Next Generation Manufacturing report (1997):

- A Company is a conventionally defined profit-making entity with "management sovereignity" and well-established bounds of ownership and liability. It is charged with responsibility and control over its own actions.

- An Extended Enterprise is a group of institutions that develop linkages, share knowledge and resources, and collaborate to create a product and/or service. This collaboration maximizes combined capabilities and allows each institution to realize its strategic goals by providing integrated solutions to customers' needs.

Consequently the Extended Enterprise is a generic systems perspective of the network of companies performing the manufacturing task. The manufacturing task may be defined by what we call the " $4 \mathrm{C}$ " model which is slightly adapted from the four strategic dimensions of the $21^{\text {st }}$ Century Manufacturing project (1991). The properties that make the network perspective interesting are:

- Customer: The purpose of the network is to be enriching to the customer. Goods is no longer the issue alone, service is paramount.

- Cooperation: The companies must cooperate to enhance competitiveness. If one company alone could provide the service, the network is not attractive.

- Communication: The network must leverage the impact of people and information, i.e. synery of the company's working together.

- Change: The companies must organize to master change and uncertainty, i.e. the network constantly adapts to the requirements.

Given this systems definition, we may apply the theories from general systems science to the networks. The systems concepts have been applied in manufacturing to internal networks e. $g$ by this working group year's back. In the following the remaining concepts are applied to the Extended Enterprise.

\subsection{Virtual organization}

Preiss (1996) defines the Virtual Organization as: "a collection of business units in which people and work processes from the business units interact intensively in order to perform work which benefits all. It is distinct from a partnership, strategic alliance, or other form of joint venture, where there may be joint ownership or joint executive control and responsibility, but in which work processes remain isolated and non-interactive. The virtual organization may be between companies, or between business units within a company, or both."

Given this definition of the Virtual Organization, we may conclude that the Virtual Organisation is a concept that focuses on a particular structure, the relationships, of the Extended Enterprise.

\subsection{Lean Production}

Lean Production (Womac, 1990) has grown out of the Toyota production system as a challenge to the traditional Fordistic mass production system. The concept focuses on quality and the reduction of waste (Womac, 1996). 
The elements of Lean Production are well-known techniques like, just-in-time manufacturing, concurrent engineering, overhead cost reduction, improved supplier and customer relationships and total quality management.

In the Extended Enterprise perspective, Lean Production adds the dimension of process improvement to the networks.

\subsection{Mass Customization}

Mass Customization (Pine, 1993) has primary focus on productivity, but also on changing customer requirements and effectiveness. Mass Customization is "the mass production of individually customized goods and services".

The concept focuses on the people and the organization, and the structuring of the products and the processes, called modularization. Compared to the Lean Production concept Mass Customization is less developed. To be able to mass customize products, leanness is required.

Applied to the Extended Enterprise, Mass Customization adds the process enhancement perspective to the framework. Process Enhancement (Victor, 1998) is achieved through learning.

\subsection{Agile Manufacturing}

Goldman defines the concept of Agility as an umbrella term (Goldman, 1995):

"It extends over a spectrum of correlated developments that together define a comprehensive change in the prevailing system of competition:

- At the level of marketing, agile competition is characterized by customerenriching, individualized combinations of products and services.

- At the level of production, agile competition is characterized by the ability to manufacture goods and to produce services to customer order in arbitrary lot sizes.

- At the level of design, agile competition is characterized by a holistic methodology that integrates supplier relations, production processes, business processes, customer relations, and the products use and eventual disposal.

- At the level of the organization, agile competition is characterized by the ability to synthesize new production capabilities out of the necessary resources - the expertise of people and the physical facilities - regardless of their physical location within a company or among groups of cooperating companies.

- At the level of management, agile competition is characterized by a shift from the command and control philosophy of the modern industrial corporation to one of leadership, motivation, support, and trust.

- At the level of people, agile competition is characterized by the emergence of a knowledgeable, skilled, and innovative total work force as the ultimate differentiator of successful companies from unsuccessful ones."

Like Mass Customization, the concept of Agile Manufacturing puts emphasis on effectiveness and Agile Manufacturing deals with customization, not only of the products but also the manufacturing system.

Agility in the Extended Enterprise expresses the dynamic capabilities of the networks, and agility adds the dimension of process development to the framework. 


\subsection{Implications}

We have now established the background of the framework for studying interorganizational networks from a manufacturing perspective. The Extended Enterprise comprises the generic systems definition of the network, and the Virtual Organization is defined as a particular type of relationship in the networks.

Three important "post mass production" concepts have been defined to express different focal points in the Extended Enterprise concept.

In the next chapter we will establish the framework and show examples of three archetype networks.

\section{FRAMEWORK}

In this chapter the framework for classifying an Extended Enterprise is established. Industrial networks have been approached from many perspectives of which some of them may be adapted to this classification.

- The systems science provides a foundation for classifying the elements and the relationships in a network, especially from a topological view. E.g. the old classification of production structure (A-shape, V-shape, T-shape etc.) is easily enhanced to cover topologies of the Extended Enterprise.

- The production management theory, which also stems from systems science, may be used to identify the location of planning and control tasks in the Extended Enterprise. This line of thinking may be traced back to Skinner.

- The old ideas of coordination mechanisms from the contingency theory offer concepts for classifying the relationships in the Extended Enterprise.

- From the economic theory we have the transaction costs theory to explain why networks are structure in market, hierarchies or the intermediaries.

- The International Marketing and Purchasing project defines a number of variables to describe the interaction processes between the seller and buyer.

Other perspectives may be included in the framework: competence, learning, culture, etc., but here we concentrate on the manufacturing perspective.

The manufacturing concepts covered in the previous chapter highlights three important dimensions of the Extended Enterprise by which the networks are characterized: The network performance, adaptability and the interaction in the network.

\subsection{Network performance}

The development of manufacturing concepts from mass production towards agile manufacturing represents a development of performance focus from a static internal productivity towards external dynamic effectivenes (discussed in Møller, 95). This development is probably a consequence of increased customer focus over the years, but there is a natural trade-off between productivity and effectiveness that must be observed.

\subsection{Network adaptability}

Mass Production emerged in a stable environment. The Lean Production concept introduced continous improvements of the processes as a means to adapt 
to variations. Mass Customization operates with product configuration to adapt to customer requirements and Agile Manufacturing also considers configuration of the processes and the network as a reaction towards change in the markets. The networks can either focus on flexibility on produtcs or processes.

\subsection{Network interaction}

The shared tasks in a network create different interaction patterns. The Mass Production interaction is none or limited to operations. In other words, the interactions are the rudimentary logistics processes. Lean Production introduces shared responsibility for process improvement, e.g. suppliers are helped to improve quality. In Mass Customization the complexity of the shared tasks are taken one step further to process enhancement, the suppliers are involved in development. In Agile Manufacturing the integration is complete, and process innovation is a shared task, i.e. the supplier may initiate development.

\subsection{Network classes}

The three dimensions are important to classify the networks, and to illustrate the framework, we will introduce three achetypes of Extended Enterprise.

Type I - "The Supply Chain": A dominating company characterizes this type of network, as is the case in the automotive industry. Other examples are larger companies producing engineered facilities; they draw on a large number of suppliers. This type corresponds to what Wiendahl \& Helms denote strategical network (Wiendahl, 1997).

The dominating company is extending its view and scope of operation; it will take the lead and set the pace. Mutual benefits may be evaluated rather clearly from the objectives and operation of the dominating company. We would expect to find well-structured relationships. The network will be striving to be lean, but will probably never be agile, because the resources of the suppliers are not valued.

Type II - "The Virtual Company": This type of network is characterized by complementary contributions from a number of different companies, and with the interaction pattern of the Virtual Organization. One company plays the role of a broker. Examples include a consortium for a construction project encompassing architects, civil and construction engineers as well as construction companies and suppliers. Tatsiopoulos (1997) gives several examples of companies working together on a public bid for an order in the clothing industry. Most projects are in reality a virtual company, because they seek to realize a complex task by drawing on contributions from complementary partners who are also stakeholders.

There is per se no leader in the virtual company. The power structure will depend on the balance between each partner's contribution and benefit, cf. the coalition model introduced by March \& Simon. The virtual enterprise may be vulnerable and unstable, because its survival depends on the willingness of all the partners to deliver the agreed-upon contribution. One single partner may prohibit the virtual enterprise from delivering its product. The network is likely to be lean, because that would be part of the entrance ticket to the network. Agility may be large; but it will depend on the strength of the coalition and the mutual trust, which have developed. In general, it takes time to establish a new balance. 
Type III - "The Task Force": "The Task Force" only exsists to do a specific task, and may be characterized as a self-controled or autonomous network. The gradual emergence of predominantly informal relationships between companies with no extensive contract, but rather a more or less tacit agreement of norms of conduct characterizes this type of network. The Internet is probably the best example of a self-controlled network. Other examples include companies participating in a common purchase association, a confederation of companies from the same industry, and R\&D network, often of competing companies.

As in the case of the previous situation, if the mutual benefit of cooperation is evident to all partners, the self-controlled network may become quite stable. New companies may easily join the network, and others may leave the network.

This network is agile because if the degree of interaction was not needed to be high, the network was never established. The network is not necessarily lean because the value of the products may be so high that productivity is unimportant.

\section{CONCLUSIONS}

The introduction of the three network classes covers a spectrum of distinctly different relationships and different processes and emerging structures. The discussion of the essential features of the network classes illustrates this point.

\subsection{Implications}

It seems reasonable to expect that the "Supply Chain" will be governed by a large number of formal procedures and systems, whereas the "Task Force" probably will fall apart, if strict formal systems were introduced. In several extended enterprises, the dominating company simply dictates which formal management system to use.

As Tatsiopoulos has indicated, the "Virtual Company" in his example displayed difficulties in applying a PMS originally geared to a single company (Tatsiopoulos, 97). On the other hand, the "Virtual Company" will be more dependent upon the development of mutual trust than will the "Supply Chain".

Organization theory discusses various new forms of cooperation, e.g. loosely coupled systems and voluntary networks. Such forms might be compared with the types of networks introduced.

The nature of learning taking place between companies in the network most likely will vary. So will the conditions for learning to take place at all.

The literature and practice use concepts such as strategic alliance and partnership. We may use the classification to discuss differences in nature and focal points for the three types of network. In this way, we achieve a broader understanding of the two concepts.

A company may use the classification in at least two ways. First, it may realize that one type completely describes the present situation. Then, the company may draw from the implications discussed above to identify its strategical and tactical focal areas.

Alternatively, the company may realize that different perceptions of the type of networks exist in the company and within the network. One industrial enterprise may view itself as the dominating company in an extended enterprise. Yet, 
adoption of a "Virtual Company" picture may disclose that, in fact, another company by virtue of its real power holds the key to successful operation of the network.

In this way, the three types may represent three different pictures (paradigms, perspectives) of the relationships between companies in a network. Using all three interchangeably may provide a deeper understanding of the observed behavior.

Another application is to identify trends and shifts of paradigm. To illustrate this point, a major shipyard is considering moving in the direction of the virtual enterprise away from it traditional role as the dominating company in a "Supply Chain" network. The reason is that international competition forces the shipyard to seek suppliers that at any point in time is the best. This require a looser relationship than developed in the "Supply Chain" network.

Other examples point in the opposite direction. Companies in the building and construction industry traditionally have followed the "Virtual Company" paradigm. Evidently a higher productivity could be achieved, if the "Supply Chain" could be adopted, mainly because of the potential for reducing the large amount of waste in the current operation of the network.

\subsection{Conclusion}

This paper's contribution is to clarify and to combine several manufacturing concepts into a new theoretical framework, but more importantly the paper has started a discussion of the classification of interorganizational networks, which should be expanded in the future. The three different network types have different characteristics. Although by far not complete the implications and applications outlined suggest that it will be beneficial to pursue this line of thought.

\section{REFERENCES}

"21st Century Manufacturing Enterprise Strategy - An Industry Led View" (1991) Iacocca Institute

"Next Generation Manufacturing - A Framework for Action" (1997) Agility Forum, Leaders for Manufacturing, and Technologies Enabling Agile Manufacturing

Goldman, S. L., Roger N. Nagel \& Kenneth Preiss (1995) "Agile Competitors and Virtual Organizations - Strategies for Enriching the Customer", Van Nostrand Reinhold

Kidd, P.T. (1994) "Agile Manufacturing - Forging New Frontiers", AddisonWesley

Moller, C. (1995) "Logistics Concept Development - Towards a Theory for Designing Effective Systems", Ph.D. Thesis, Aalborg University

Pine, B. Joseph II (1992) "Mass Customization - The New Frontier in Business Competition", Harvard Business School Press

Preiss, K.; Steven L. Goldman, Roger N. Nagel (1996) "Cooperate to Compete Building Agile Business Relationships", Van Nostrand Reinhold

Riis, J. O. (1994) "Situational Production Management: A Practical Theory for the Development and Application of Production Management", Production Planning \& Control, Vol 5, No. 3

Schönsleben, P.; A. Büchel (1997) "Organizing the Extended Enterprise", Proceedings of IFIP WG 5.7 1997 Working Conference, Ascona, Switzerland 
Tatsiopopulos, I.P. \& I.A. Pappas \& S. Ponis (1997) "Clothing Industry 2000: The Archetype of the Extended Enterprise", in Proceedings of IFIP WG 5.7 1997 Working Conference (Chairmen P. Schönsleben, A. Büchel) Ascona, Switzerland

Victor, B. \& Andy Boynton (1998) "Invented Here: Maximizing Your Organization 's Internal Growth and Profitability", Harvard Business Press

Wiendahl, H.P. \& K. Helms (1997) "Variable Production Networks - Successful Acting in an "Alliance of the Best"', in Proceedings of IFIP WG 5.71997 Working Conference (Chairmen P. Schönsleben, A. Büchel) Ascona, Switzerland

Womac, J. P., Daniel T. Jones, David Ross (1990) "The Machine that Changed the World', Rawson Associates

Womac, J.P. \& Daniel T. Jones (1996) "Lean Thinking - Banish Waste and Create Wealth in Your Corporation", Simon \& Schuster 